\title{
Evaluation of Traumatic Spine by Magnetic Resonance Imaging and Correlation with Neurological Recovery
}

\author{
Sarita Magu ${ }^{1}$, Deepak Singh ${ }^{2}$, Rohtas Kanwar $\operatorname{Yadav}^{1}$, Manju Bala ${ }^{3}$ \\ ${ }^{1}$ Deparment of Radiodiagnosis, Pandit Bhagwat Dayal Sharma Post Graduate Institute of Medical Sciences (PGIMS), Rohtak, India \\ ${ }^{2}$ Department of Radiodiagnosis, Shree Guru Gobind Singh Tricentenary Medical College, Gurgaon, India \\ ${ }^{3}$ Department of Anaesthesiology, Pandit Bhagwat Dayal Sharma Post Graduate Institute of Medical Sciences (PGIMS), Rohtak, India
}

Study Design: Prospective study.

Purpose: To compare magnetic resonance imaging (MRI) findings with clinical profile and neurological status of the patient and to correlate the MRI findings with neurological recovery of the patients and predict the outcome.

Overview of Literature: Previous studies have reported poor neurological recovery in patients with cord hemorrhage, as compared to cord edema in spine injury patients. High canal compromise, cord compression along with higher extent of cord injury also carries poor prognostic value.

Methods: Neurological status of patients was assessed at the time of admission and discharge in as accordance with the American Spine Injury Association (ASIA) impairment scale. Mean stay in hospital was $14.11 \pm 5.74$ days. Neurological status at admission and neurological recovery at discharge was compared with various qualitative cord findings and quantitative parameters on MRI. In 27

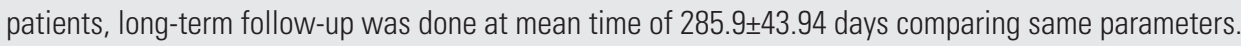

Results: Cord edema and normal cord was associated with favorable neurological outcome. Cord contusion showed lesser neurological recovery, as compared to cord edema. Cord hemorrhage was associated with worst neurological status at admission and poor neurological recovery. Mean canal compromise (MCC), mean spinal cord compression (MSCC) and lesion length values were higher in patients presenting with ASIA A impairment scale injury and showed decreasing trends towards ASIA E impairment scale injury. Patients showing neurological recovery had lower mean MCC, MSCC, and lesion length, as compared to patients showing no neurological recovery $(p<0.05)$.

Conclusions: Cord hemorrhage, higher MCC, MSCC, and lesion length values have poor prognostic value in spine injury patients.

Keywords: Spine injuries; Cord hemorrhage; Cord contusion; Mean canal compromise; Mean spinal cord compression

\section{Introduction}

Spinal trauma occurs with an annual incidence of approximately 15 to 40 cases per million. It commonly results from motor vehicle accident, fall from height, community violence and workplace related injury [1]. The incidence in South Asia is around 21 per million [2]. Trauma to the spine and spinal cord is a potentially devastating injury.

Received Jan 12, 2015; Revised Feb 21, 2015; Accepted Feb 21, 2015

Corresponding author: Deepak Singh

Department of Radiodiagnosis, Shree Guru Gobind Singh Tricentenary Medical College, Gurgaon 122001, India

Tel: +91-999-272-1870, Fax: +91-124-227-8232, E-mail: deepakphogat266@gmail.com 
The incidence of spinal cord injury (SCI) is more common in young male patients, occurring most frequently in persons between 16 and 40 years of age. Imaging studies are essential to confirm the exact location of the injury, to assess the stability of the spine, and to define the repercussion of the trauma on the diameters of the spinal canal and neural foramina. The advent of magnetic resonance imaging (MRI) has made it possible to accurately characterize the underlying SCI even when radiographs and computerized tomography (CT) scan are normal. MRI, with superior tissue characterization, provides the best evaluation of soft tissue pathology and is essentially the only direct evaluation of the spinal cord and nerve roots. Several types of traumatic spinal cord lesions can be found: intramedullary hemorrhage, spinal cord contusion/edema, extrinsic compression by a bone fragment or a traumatic disc herniation, and even complete transection of the cord [3]. MRI helps in predicting neurological recovery. Neurological recovery is usually insignificant in patients with intramedullary hemorrhage or cord transection, whereas patients with cord edema or contusion may significantly recover from neurological dysfunction [4]. Plain radiographs, and even multidetector computed tomography, do not rule out injury to the spinal cord [5]. Quantitative measurements for evaluating spinal trauma like mean canal compromise (MCC), mean spinal cord compression (MSCC), and lesion length of cord are also important in predicting the severity of damage and predicting recovery [6]. The aim of our study was to compare MRI findings with clinical profile and neurological status of the patient and to correlate the MRI findings with neurological recovery of the patients and predict the outcome.

\section{Materials and Methods}

Fifty-seven patients of acute SCI were included in the study from among the patients reporting within 72 hours of the injury for treatment at Department of Radiodiagnosis in Pandit Bhagwat Dayal Sharma Post Graduate Institute of Medical Sciences (Rohtak, India) between the periods of January 2012 to May 2014. Prior written informed consent was obtained from each patient after explaining the procedure, risks and benefits. The included patients were with either injury on radiograph or radiographically normal patients with neurologic deficit. All the patients underwent X-ray, and MRI examinations and 36 patients underwent $\mathrm{CT}$ scans as well, within 72 hours of injury. The neurological status of the patients was compared at admission and discharge and correlated with the MRI findings. The mean period of stay in hospital was 14.11 \pm 5.74 days. In 27 patients, the long-term follow-up was done at a mean time of $285.9 \pm 43.94$ days comparing the same parameters.

\section{Inclusion criteria}

All patients of acute spine injury or suspected SCI with neurological deficits presenting within 72 hours of injury were included.

\section{Exclusion criteria}

(1) Patients presenting after 72 hours of injury. (2) Patients with non-traumatic cause for SCI. (3) Non-cooperative patients. (4) Medically unstable patients. (5) Patients with previous implanted metallic devices. (6) Patients with claustrophobia, pacemakers, and cochlear implants. (7) Patients presenting with previous neurological deficits. (8) Fractures in pathological bone.

Patient assessment was done by taking detailed history of the patient in a chronological order. Thorough general physical examination and neurological examination of the patient was performed at the time of admission and at the time of discharge according to international guidelines. All the patients were given methyl prednisolone and scanned just after resuscitation. Twenty-one patients were managed by surgical decompression and pedicle screw fixation for spine stability after initial spine immobilization. Others were managed conservatively with spine immobilization using braces. Patients were placed in various groups based on American Spinal Injury Association (ASIA) impairment scale [4,7]. Change in ASIA impairment scale toward lower grade between admission and discharge was considered neurological recovery.

\section{Qualitative cord changes}

The abnormal signal if seen from spinal cord on MRI of the patients was divided into three categories. (1) Cord hemorrhage with edema: seen as low signal intensity images surrounded by thin rim of high signal intensity edema on T2-weighted image (T2WI) and heterogeneous signal on T1-weighted image (T1WI) within 24 hours which changes to heterogeneous signal pattern on T2WI 
between 48 hours to 1 week (Fig. 1A). (2) Cord contusion with edema: seen as area of intermediate to low intensity signal on T2WI surrounded by thick rim of high signal intensity edema on T2WI and normal signal intensity on T1WI, the signal persists in subacute period (Fig. 1B). (3) Cord edema only: seen as uniform high signal intensity on T2WI and normal intensity on T1WI (Fig. 1C) [8].

Quantitative parameters assessed spinal trauma were also evaluated by quantitative criteria of MCC, MSCC, and lesion length of the cord.

$$
\mathrm{MCC}=\left(1-\frac{\frac{\mathrm{Di}}{\mathrm{Da}+\mathrm{Db}}}{2}\right) \times 100
$$

Di is the mid sagittal diameter of canal at injury level and $\mathrm{Da}$ and $\mathrm{Db}$ is the mid sagittal diameter of canal one segment above and below the injury level. T1WI was used to calculate MCC (Fig. 2A).

$$
\text { MSCC }=\left(1-\frac{\mathrm{di}}{\frac{\mathrm{da}+\mathrm{db}}{2}}\right) \times 100
$$

di is the mid sagittal diameter of cord at injury site and $\mathrm{da}$ and $\mathrm{db}$ is the diameter at one segment above and below, respectively. T2WI was used to calculate the values for MSCC (Fig. 2B). In some cases where the injury was seen at the terminal end of cord the only da was taken instead of average value of $\mathrm{da}$ and $\mathrm{db}$. MSCC taken as nil when the injury was at the level below the termination of cord and no injury was seen in cord. MCC and MSCC were taken as percentage values.

Lesion length was measured in millimeters as the length of abnormal signal from cord in craniocaudal direction on T2WI (Fig. 2C). This included signals from cord edema, cord contusion, and cord hemorrhage [6,9]. MRI scans were done within 72 hours of injury in all cases in a machine with superconducting magnet of 1.5-Tesla strength; patients were examined in supine position with quiet breathing. Four-millimeter slice thickness was used for images. Field of view (FOV) for sagittal images was $325 \mathrm{~mm}$ and flip angle (FA) was 90 degree. FOV for axial image was $225 \mathrm{~mm}$ and FA was 90 degree. Coronal images were acquired if required with $\mathrm{FOV}$ of $325 \mathrm{~mm}$ and FA of 90 degree.

\section{Statistical methods}

All the statistical analyses and computation were per-
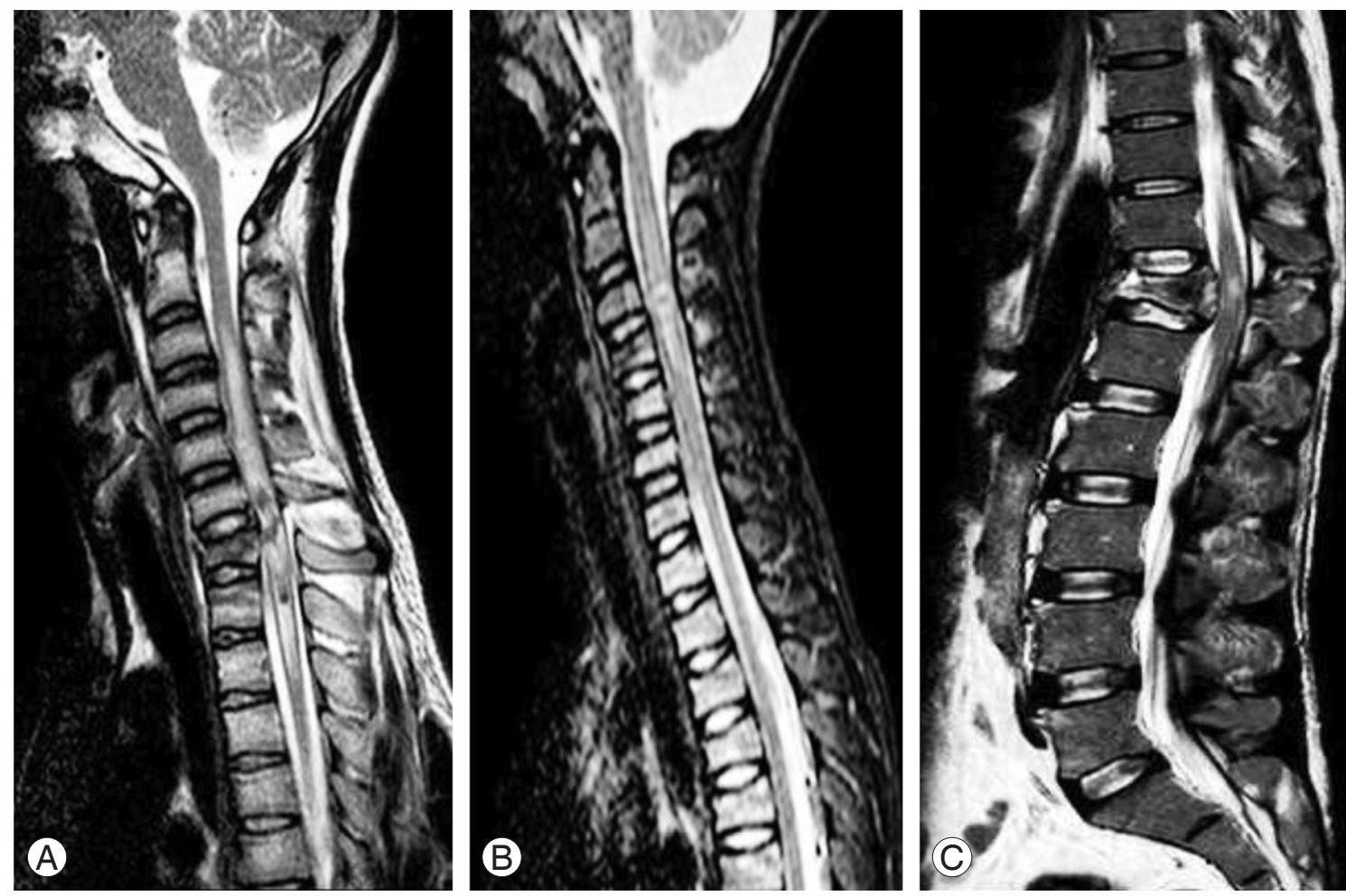

Fig. 1. (A) Cord hemorrhage pattern seen as heterogeneous pattern of signal intensity from cord on T2-weighted image (T2WI). (B) Cord contusion pattern seen as focus of low intensity contusion surrounded by rim of high intensity signal edema on T2WI. (C) Cord edema pattern seen as high signal intensity from cord on T2WI. 

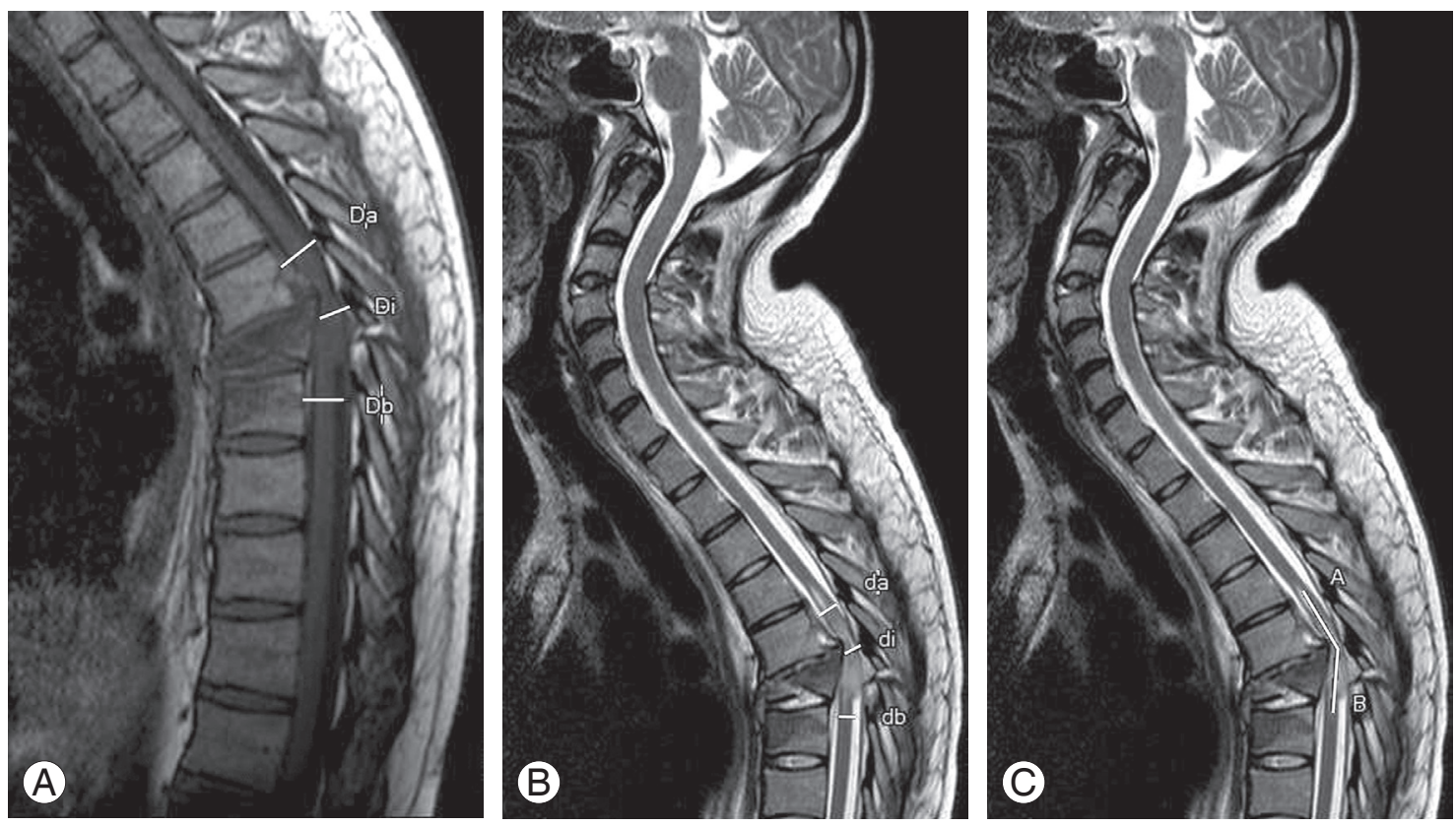

Fig. 2. (A) Mean canal compromise calculation on T1-weighted image (T1WI). Da and Db are canal diameter one segment above and below the injury level respectively and Di is the canal diameter at injury level [10]. (B) Mean spinal cord compression calculation on T2WI. da and db are the cord diameter one segment and above and below the injury level respectively and di is the cord diameter at injury level [10]. (C) Lesion length measurement on T2WI. Altered signal from cord is seen between Point A and B [10].

formed using SPSS ver. 10.0 (SPSS Inc., Chicago, IL, USA). The correlative studies were assessed statistically by applying Pearson chi-square test for qualitative parameters and analysis of variance (ANOVA) for quantitative parameters. The statistical significance level accepted was $p<0.05$.

\section{Results}

\section{Epidemiology}

Out of 57 patients, 42 (73.7\%) were males and 15 (26.3\%) were females. Male to female ratio was 2.8:1. Majority of patients were in age group of 21-40 years (54\%). Mean age of patient was $35.39 \pm 13.91$ years. The mean time taken to perform MRI was $29.5 \pm 12.58$ hours after injury. The level injury was shown in Table 1 . In 55 patients (96.4\%), the cause of injury was either fall from height (50.9\%) or road side accident (45.6\%). One patient had a history of fall of weight on patient $(1.8 \%)$ and one with assault $(1.8 \%)$.

\section{Neurological status}

SCI was grouped into five categories based on the ASIA
Table 1. Level of injury ( $n=57)$

\begin{tabular}{lc} 
Level of injury & No. $(\%)$ \\
\hline Cervical & $12(21.1)$ \\
\hline Thoracic & $5(8.8)$ \\
\hline Thoracolumbar & $30(52.6)$ \\
\hline Lumbar & $10(17.5)$ \\
\hline
\end{tabular}

impairment scale at the time of admission. Most common presentation was ASIA A impairment scale injury in $43.9 \%$ of patients (Table 2 ).

\section{Radiographic injury}

Out of total 57 patients, 49 (86\%) showed fracture or dislocation on the X-ray. Eight patients (14\%) had normal $\mathrm{X}$-rays and were included in SCI without radiographic abnormality group.

\section{Spinal cord changes}

Most common lesion seen was cord edema in 15 (26.3\%); cord hemorrhage and cord contusion was seen in $13 \mathrm{pa}-$ 
Table 2. Neurological status of patients with different cord findings ( $n=57)$

\begin{tabular}{lccccccc} 
& No. of & & \multicolumn{2}{c}{ American Spine Injury Association impairment scale } & & \\
\cline { 3 - 7 } Cord finding & patients & A & B & C & D & & E \\
Cord hemorrhage with edema & 13 & $13(100)$ & 0 & 0 & 0 & 0 & $<0.001$ \\
Cord contusion with edema & 13 & $9(69.2)$ & $2(15.4)$ & $2(15.4)$ & 0 & 0 & $<0.001$ \\
\hline Only cord edema & 15 & $2(13.3)$ & $5(33.3)$ & $5(33.3)$ & $2(13.3)$ & $1(6.7)$ & 0.032 \\
Normal cord & 16 & $1(6.0)$ & 0 & $4(25.0)$ & $4(25.0)$ & $7(43.7)$ & $<0.001$ \\
\hline
\end{tabular}

Values are presented as number (\%).

Table 3. Mean MCC, MSCC, and lesion length value with the neurological status

\begin{tabular}{lccccccc} 
& \multicolumn{5}{c}{ American Spine Injury Association impairment scale } & $p$-value \\
\cline { 2 - 7 } Quantitative parameter & A & B & C & D & E & \\
MCC & $49.32 \pm 24.1$ & $27.29 \pm 15.9$ & $39.09 \pm 21.3$ & $26.83 \pm 24.3$ & $20.63 \pm 24.3$ & 0.011 \\
MSCC & $30.72 \pm 28.2$ & $12.57 \pm 15.6$ & $18.73 \pm 18.2$ & $5.0 \pm 12.2$ & $1.75 \pm 4.9$ & 0.009 \\
Lesion length & $74.2 \pm 58.1$ & $37.14 \pm 39.5$ & $13.0 \pm 16.5$ & $5.5 \pm 8.9$ & $2.8 \pm 5.3$ & $<0.001$ \\
\hline
\end{tabular}

Values are presented mean \pm standard deviation.

MCC, mean canal compromise; MSCC, mean spinal cord compression.

tients $(22.8 \%)$ each. Normal cord was seen in 16 patients (28.1\%) (Table 2).

\section{Correlation of qualitative parameters of cord with neurological status at admission}

Cord changes were correlated with the initial neurological status at the time of admission. In all the patients with cord hemorrhage, initial neurological status was ASIA A. Nine patients $(69.2 \%)$ having contusion pattern on MRI had ASIA A status where as only two patients (13.3\%) with only cord edema had ASIA A status at admission (Table 2). This data was statistically significant of applying Pearson chi-square test $(p<0.05)$.

\section{Correlation of quantitative parameters with neuro- logical status at admission}

The mean scores of MCC, MSCC, and lesion length were calculated in different neurological group according to ASIA impairment scale. The average of MCC, MSCC, and lesion length was more for complete SCI (ASIA A) than incomplete SCI (ASIA B, C, and D) and least for neurologically normal patients (ASIA E) (Table 3). The data was statistically significant on application of ANOVA with the individual $p<0.05$ as shown in Table 3.

\section{Neurological recovery}

Thirty-six percent of patients with complete SCI (ASIA A) showed some level of improvement in their neurological status over the period of hospital stay; whereas, all the patients with incomplete SCI (ASIA B, C, and D) showed some improvement (Table 4).

Only two patients (15.4\%) with cord hemorrhage in initial MRI showed improvement in neurological status. In patients with cord contusion pattern, improvement in neurological status was seen in nine patients (69.2\%); and in patients with cord edema only, improvement was seen in 13 patients (86.7\%) (Table 5). On long-term follow-up in 27 patients, similar trend was observed as cord hemorrhage pattern showed no neurological recovery even on long-term follow-up and contusion showed recovery in four patients (57.1\%) (Table 6).

Mean MCC value for patients showing no improvement in neurological grade was $52.88 \% \pm 21.86 \%$ and the mean MCC value in patients showing improvement was $35.42 \% \pm 22.94 \%$. Mean MSCC value in patients showing no improvement was $40.44 \% \pm 29.45 \%$ and for the patients showing improvement mean MSCC value was 
Table 4. Neurological recovery of patients with initial neurological status ( $n=57)$

\begin{tabular}{lrrr} 
Impairment scale at admission & No. of patient & Improvement, no. (\%) & NA \\
ASIA A & 25 & $9(36)$ & 0 \\
ASIA B & 7 & $11(100)$ & 0 \\
ASIA C & 11 & $6(100)$ & 0 \\
ASIA D & 6 & 0 & $8(100)$ \\
ASIA E & 8 & & 0 \\
\hline
\end{tabular}

NA, not applicable; ASIA, American Spine Injury Association.

Table 5. Neurological recovery in patients with different cord findings ( $n=57)$

\begin{tabular}{|c|c|c|c|c|c|}
\hline Finding on cord & $\begin{array}{l}\text { No. of } \\
\text { patient }\end{array}$ & $\begin{array}{l}\text { No. of patient with } \\
\text { neurological } \\
\text { impairment }\end{array}$ & $\begin{array}{l}\text { Patient showing } \\
\text { improvement }\end{array}$ & $\begin{array}{l}\text { Patient showing } \\
\text { no improvement }\end{array}$ & $p$-value \\
\hline Cord hemorrhage & 13 & 13 & $2(15.4)$ & $11(84.6)$ & $<0.001$ \\
\hline Cord contusion & 13 & 13 & $9(69.2)$ & $4(31.8)$ & 0.028 \\
\hline Cord edema only & 15 & 14 & 13 (86.7) & $1(13.3)$ & 0.045 \\
\hline Normal cord & 16 & 9 & $9(100)$ & 0 & $<0.001$ \\
\hline
\end{tabular}

Values are presented as number (\%).

Table 6. Cord findings on initial MRI, follow-up MRI, and neurological recovery ( $n=27)$

\begin{tabular}{|c|c|c|c|c|c|}
\hline Cord finding & $\begin{array}{l}\text { No. of } \\
\text { patient with } \\
\text { initial MRI }\end{array}$ & $\begin{array}{l}\text { No. of patient with } \\
\text { abnormal cord signal } \\
\text { on follow-up MRI }\end{array}$ & $\begin{array}{c}\text { No. of patient with } \\
\text { neurological impairment } \\
\text { at admission }\end{array}$ & $\begin{array}{l}\text { Neurological } \\
\text { recovery at } \\
\text { long-term follow-up }\end{array}$ & $p$-value \\
\hline Cord hemorrhage & 2 & 2 & 2 & 0 & 0.023 \\
\hline Cord contusion & 7 & 3 & 7 & $4(57.1)$ & 0.020 \\
\hline Cord edema & 8 & 1 & 8 & $8(100)$ & 0.008 \\
\hline Normal cord & 10 & 0 & 7 & $7(100)$ & 0.002 \\
\hline
\end{tabular}

Values are presented as number (\%).

$\mathrm{MRI}$, magnetic resonance imaging.

Table 7. Improvement of neurological status with correlation with quantitative parameters ( $n=57)$

\begin{tabular}{|c|c|c|c|c|}
\hline $\begin{array}{l}\text { Quantitative } \\
\text { parameter }\end{array}$ & $\begin{array}{l}\text { Mean value for group } \\
\text { showing no neurological } \\
\text { improvement ( } \mathrm{n}=16)\end{array}$ & $\begin{array}{l}\text { Mean value for group } \\
\text { showing neurological } \\
\text { improvement }(n=33)\end{array}$ & $\begin{array}{c}\text { Mean value for } \\
\text { neurological normal } \\
\text { group }(n=8)\end{array}$ & $p$-value \\
\hline MCC (\%) & $52.88 \pm 21.8$ & $35.42 \pm 22.9$ & $20.62 \pm 18.8$ & 0.004 \\
\hline $\operatorname{MSCC}(\%)$ & $40.44 \pm 29.4$ & $13.48 \pm 16.0$ & $1.75 \pm 4.9$ & $<0.001$ \\
\hline Lesion length (mm) & $94.9 \pm 62.5$ & $23.39 \pm 26.3$ & $2.88 \pm 5.3$ & $<0.001$ \\
\hline
\end{tabular}

Values are presented mean \pm standard deviation.

MCC, mean canal compromise; MSCC, mean spinal cord compression.

$13.48 \% \pm 16.01 \%$. Mean lesion length in patients showing no improvement in neurological status was $94.9 \pm 62.53$ $\mathrm{mm}$ and the mean values of lesion length for the group showing improvement was $23.39 \pm 26.34 \mathrm{~mm}$ (Table 7).
On long-term follow-up in 27 patients, higher value of MCC, MSCC, and lesion length was seen on initial MRI in patients showing no neurological recovery even on long-term follow-up, as compared to patients showing 
neurological recovery.

\section{Discussion}

The male to female ratio of our study was $2.8: 1$. Singh et al. [11] in their study of epidemiology of spinal trauma patients in the same region as ours had observed the male to female ratio of 2.9:1.

Agarwal et al. [12] also reported the most common age group as 20-39 years. In their study Singh et al. [11] had a mean age of 35.4 years. Katzberg et al. [13] had a mean age of 37.8 years in spinal trauma patients in their study. Chiu et al. [14] reported most common cause of injury in developing world, as fall from height followed by road side accident. In developed countries, the most common cause is road side accident followed by fall from height.

The most common neurological status was ASIA A in about 25 patients (43.9\%). Similar results were reported by Parashari et al. [15] who reported $41.93 \%$ patients in ASIA A group; Andreoli et al. [16] reported $42 \%$ in group ASIA A and Ramon et al. [17] reported 51\%.

The distribution of patients in different group as per ASIA impairment scale in our study showed that the most common neurological status as ASIA A (43.9\%), followed by ASIA C (19.3\%). Least common neurological status was ASIA D (10.5\%). Parashari et al. [15] reported most common neurological status as ASIA A (41.9\%), followed by ASIA D (27.4\%); however, Mahmood et al. [18] and Flanders et al. [19] had ASIA D (42.15\%) and ASIA E $(30.8 \%)$ as the most common group, respectively, in their study.

Pattern described in our study was similar to patterns described by Ramon et al. [17], Mahmood et al. [18], and Bondurant et al. [20]. However, the cord lesion described by Kulkarni et al. [4] comprised of type I: as T2WI showing large area of hypointensity surrounded by thin rim of hyper intensity and T1WI as inhomogeneous signals; type II: as central hyperintensity surrounded by hyper intensity on T2WI and normal intensity on T1WI; type III: as small area of central hypointensity surrounded by thick hyperintensity.

In our study, 13 patients (22.8\%) had cord hemorrhage; $13(22.8 \%)$ had cord contusion; 15 (26.3\%) had cord edema and 16 (28.1\%) had normal cord on MRI. Cord abnormality was seen in 47 patients $(75.8 \%)$ out of 62 patients by Parashari et al. [15] and in 19 patients (70\%) out of total 27 patients by Kulkarni et al. [4].
Miyanji et al. [6] observed that patients with complete SCI (ASIA A) had more MCC $(p=0.005)$, MSCC $(p=0.002)$, and lesion length ( $p=0.005)$, as compared to incomplete SCI or neurologically normal status. Although the final outcome of neurological recovery was more strongly correlated to the spinal cord compression than canal compromise. Haar et al. [10] also found a positive correlation between the complete SCI on Frankel grade with the MCC ( $p=0.009)$, MSCC ( $p=0.008)$, and Lesion Length $(p=0.001)$. Similar results were reported by Furlan et al. [21].

The patients with ASIA A impairment scale showed improvement in $36 \%$ of cases only; whereas, all the patients in ASIA B, C, and D grade of injury showed some level of improvement.

Parashari et al. [15] reported that out of total 62 patients in their study; $30.65 \%$ of patients showed improvement and $43.5 \%$ of patients showed no improvement; furthermore, $23 \%$ of the patients with ASIA A grade injury improved in their study. Harrop et al. [22] reported that 7\% of ASIA A impairment scale patients had improvement, whereas $94 \%$ of cases in ASIA D category had some improvement. Rao et al. [23] reported that none of the patients with ASIA A impairment scale neurological injury showed improvement and all the patients of group ASIA D improved.

We observed that out of 13 patients with cord hemorrhage with edema pattern, only two patients (15.45\%) had shown improvement $(p<0.001)$; out of 13 patients with cord contusion, nine patients $(69.2 \%)$ had shown improvement $(p=0.028)$ and out of 14 patients with cord edema only with neurological deficit at admission, $13 \mathrm{pa}$ tients (86.2\%) had shown improvement over the period of hospital stay $(p=0.045)$.

Ramon et al. [17], Bondurant et al. [20], Mahmood et al. [18], and Tewari et al. [24] had reported that cord hemorrhage was associated with poor neurological outcome, as compared to contusion or edema pattern. Rao et al. [23] in their study also observed that the $84 \%$ of patients of edema less than three segments long had improvement, as compared to $16.6 \%$ of patients with improvement of edema more than three segments involved.

Haar et al. [10] also concluded that the lesion length $(p=0.011)$ and MSCC $(p=0.063)$ are predictors of poor neurological recovery. Miyanji et al. [6], Fehlings et al. [25] and Rao et al. [23] also studied the quantitative variables and their relationship with neurological status and found 
a significant correlation between the poor neurological recovery and severity of MSCC and lesion length.

\section{Conclusions}

MRI is an excellent available tool for depicting the changes within the injured spine. It allows the radiologist to directly evaluate the soft tissue of spine like ligaments and disc in a case of trauma. It differentiates between spinal cord edema, contusion and hemorrhage, each of which has different prognostic implications for the patients. Cord edema and normal cord in a case of injury is associated with favorable neurological outcome. Cord contusion shows lesser neurological recovery, as compared to cord edema and normal cord. Cord hemorrhage is associated with complete SCI and poor neurological recovery. MRI is also the modality of choice to assess the extent of cord lesion, as well as amount of canal compromise and cord compression. The severity of canal compromise, cord compression, and lesion length have a direct relationship with poor neurological outcome.

\section{Conflict of Interest}

No potential conflict of interest relevant to this article was reported.

\section{Acknowledgments}

Residents and Staff members of Department of Radiodiagnosis Pt. B.D. Sharma Post Graduate Institute of Medical Sciences Rohtak India.

\section{References}

1. Sekhon LH, Fehlings MG. Epidemiology, demographics, and pathophysiology of acute spinal cord injury. Spine (Phila Pa 1976) 2001;26(24 Suppl):S212.

2. Lee BB, Cripps RA, Fitzharris M, Wing PC. The global map for traumatic spinal cord injury epidemiology: update 2011, global incidence rate. Spinal Cord 2014;52:110-6.

3. Kerslake RW, Jaspan T, Worthington BS. Magnetic resonance imaging of spinal trauma. Br J Radiol 1991;64:386-402.

4. Kulkarni MV, McArdle CB, Kopanicky D, et al. Acute spinal cord injury: MR imaging at $1.5 \mathrm{~T}$. Radiology 1987;164:837-43.

5. Kalra V, Gulati S, Kamate M, Garg A. SCIWORAspinal cord injury without radiological abnormality. Indian J Pediatr 2006;73:829-31.

6. Miyanji F, Furlan JC, Aarabi B, Arnold PM, Fehlings MG. Acute cervical traumatic spinal cord injury: MR imaging findings correlated with neurologic outcome. Prospective study with 100 consecutive patients. Radiology 2007;243:820-7.

7. American Spinal Injury Association. International Standards for Neurological Classification of spinal cord Injury. Chicago, IL: American Spinal Injury Association; 2002.

8. Chandra J, Sheerin F, Lopez de Heredia L, et al. MRI in acute and subacute post-traumatic spinal cord injury: pictorial review. Spinal Cord 2012;50:2-7.

9. Fehlings MG, Furlan JC, Massicotte EM, et al. Interobserver and intraobserver reliability of maximum canal compromise and spinal cord compression for evaluation of acute traumatic cervical spinal cord injury. Spine (Phila Pa 1976) 2006;31:1719-25.

10. Haar MT, Naidoo SM, Govender S, Parag P, Esterhuizen TM. Acute traumatic cervical spinal cord injuries: correlating MRI findings with neurological outcome. SA Orthop J 2011;10:35-41.

11. Singh R, Sharma SC, Mittal R, Sharma A. Traumatic spinal cord injuries in Haryana: an epidemiological study. Indian J Community Med 2003;28:184-6.

12. Agarwal P, Upadhyay P, Raja K. A demographic profile of traumatic and non-traumatic spinal injury cases: a hospital-based study from India. Spinal Cord 2007;45:597-602.

13. Katzberg RW, Benedetti PF, Drake CM, et al. Acute cervical spine injuries: prospective MR imaging assessment at a level 1 trauma center. Radiology 1999; 213:203-12.

14. Chiu WT, Lin HC, Lam C, Chu SF, Chiang YH, Tsai SH. Review paper: epidemiology of traumatic spinal cord injury. Comparisons between developed and developing countries. Asia Pac J Public Health 2010;22: 9-18.

15. Parashari UC, Khanduri S, Bhadury S, et al. Diagnostic and prognostic role of MRI in spinal trauma, its comparison and correlation with clinical profile and neurological outcome, according to ASIA impairment scale. J Craniovertebr Junction Spine 2011;2:17- 
26.

16. Andreoli C, Colaiacomo MC, Rojas Beccaglia M, Di Biasi C, Casciani E, Gualdi G. MRI in the acute phase of spinal cord traumatic lesions: relationship between MRI findings and neurological outcome. Radiol Med 2005;110:636-45.

17. Ramon S, Dominguez R, Ramirez L, et al. Clinical and magnetic resonance imaging correlation in acute spinal cord injury. Spinal Cord 1997;35:664-73.

18. Mahmood NS, Kadavigere R, Avinash KR, Rao VR. Magnetic resonance imaging in acute cervical spinal cord injury: a correlative study on spinal cord changes and 1 month motor recovery. Spinal Cord 2008;46: 791-7.

19. Flanders AE, Schaefer DM, Doan HT, Mishkin MM, Gonzalez CF, Northrup BE. Acute cervical spine trauma: correlation of MR imaging findings with degree of neurologic deficit. Radiology 1990;177:25-33.

20. Bondurant FJ, Cotler HB, Kulkarni MV, McArdle CB, Harris JH Jr. Acute spinal cord injury: a study using physical examination and magnetic resonance imaging. Spine (Phila Pa 1976) 1990;15:161-8.
21. Furlan JC, Noonan V, Singh A, Fehlings MG. Assessment of impairment in patients with acute traumatic spinal cord injury: a systematic review of the literature. J Neurotrauma 2011;28:1445-77.

22. Harrop JS, Naroji S, Maltenfort MG, et al. Neurologic improvement after thoracic, thoracolumbar, and lumbar spinal cord (conus medullaris) injuries. Spine (Phila Pa 1976) 2011;36:21-5.

23. Rao KV, Vijaya Saradhi M, Purohit AK. Factors affecting long-term outcome in acute cervical cord injury. Indian J Neurotrauma 2010;7:149-55.

24. Tewari MK, Gifti DS, Singh P, et al. Diagnosis and prognostication of adult spinal cord injury without radiographic abnormality using magnetic resonance imaging: analysis of 40 patients. Surg Neurol 2005; 63:204-9.

25. Fehlings MG, Rao SC, Tator $\mathrm{CH}$, et al. The optimal radiologic method for assessing spinal canal compromise and cord compression in patients with cervical spinal cord injury: Part I. result of a multicenter study. Spine (Phila Pa 1976) 1999;24:605-13. 